Bull. Fac . Agric., Cairo Univ. , 69:291-300 (2018).

\title{
THE QUALITY OF WORK LIFE AND ITS EFFECT ON THE QUALITY OF AGRICULTURAL EXTENSION SERVICE IN MINIA GOVERNORATE
}

(Received:29.11.2018)

\section{By}

\author{
M.M.M. Abdel-Ghany
}

\begin{abstract}
Department of Rural Sociology \& Agricultural Extension, Faculty of Agriculture,
\end{abstract} Assiut University, Assiut, Egypt

\begin{abstract}
The aims of the present study were to measure the quality of the work life of the agricultural extension service from the view point of extension personnel in Minia Governorate, and to identify the effects of the quality of work life dimensions on the quality of agricultural extension service. The data were collected using a questionnaire from 220 extension employees in Minia Governorate. Frequencies, percentages, arithmetic mean, and multiple regression analysis were used for data presentation and analysis. The results indicated a decrease in the respondents' perceptions in comparison with their expectations of the quality of work life at all dimensions. It also came to clear that there is a negative gap between the respondents' perceptions compared to their expectations of the agricultural extension service quality. Multiple regression analysis showed a significant effect of all dimensions of the quality of work life on the quality of agricultural extension service, and that these dimensions explain $73 \%$ of variance in agricultural extension service quality.
\end{abstract}

Key words: Quality of Work Life, Extension Service Quality, wrklfqual, servqual, Minia Governorate

$$
\begin{gathered}
\text { جودة الحياة الوظيفية وتأثير ها على جودة الخدمة الإرشادية الزراعية بمحافظة المنيا محمد محمد محمد عبد الغني } \\
\text { محم المجتمع الريفي و الإرشاد الزراعي، كلية الزر اعة، جامعة أسيوط ، مصر }
\end{gathered}
$$

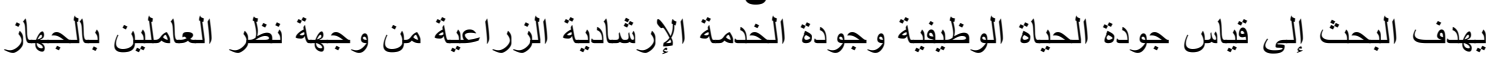

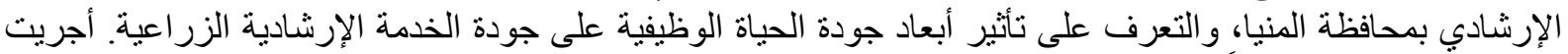

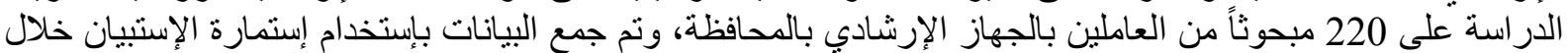

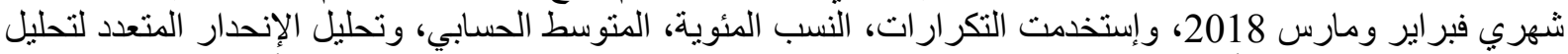

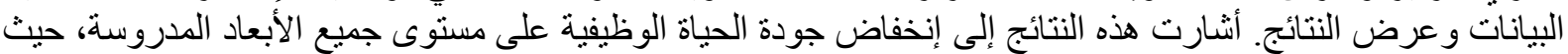

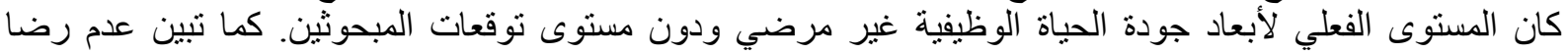

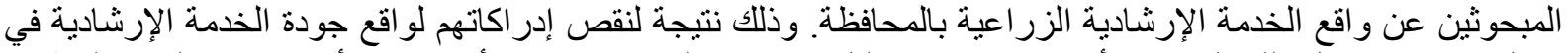

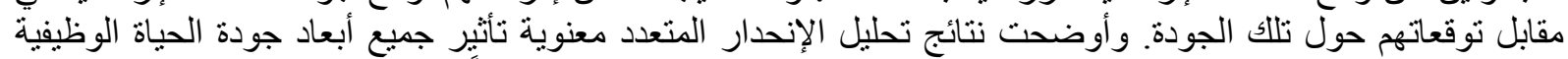

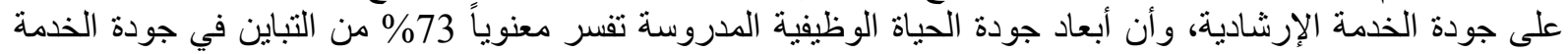
الإرشادية الزراعية.

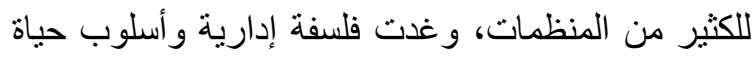

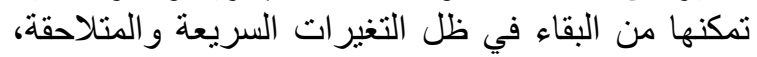

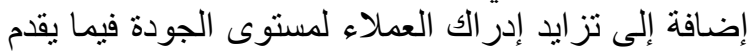

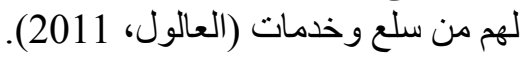

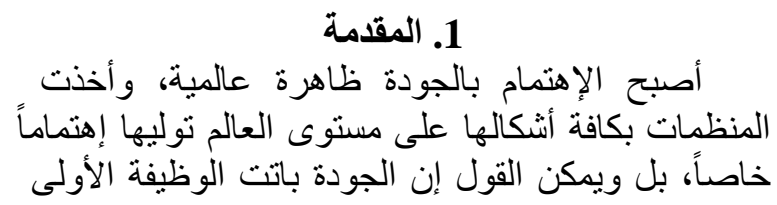

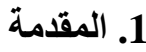

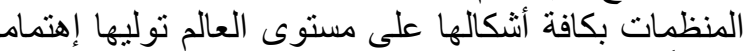
خاصاً، بل ويمكن القول إن الجودة باتت الوظيفة الأولى التى 


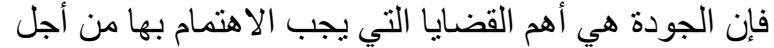

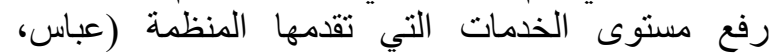
2005). و أثنار (2010) Daniel and Berinyuy (إلى فئى

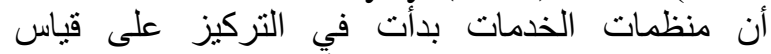

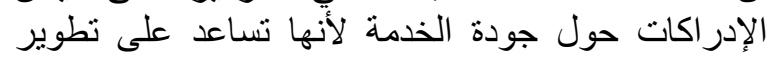

الإستر اتيجيات التي تؤدي إلى تحسين الخدمات الخدات المقدمة.

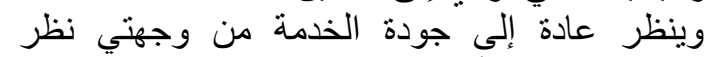

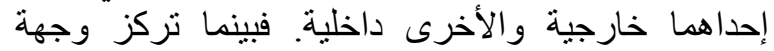

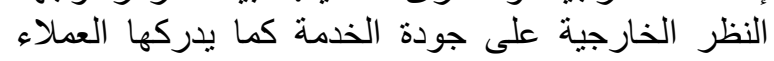

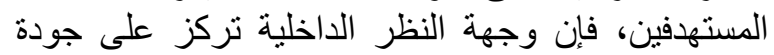
الخدمة من وجهة نظر العاملين بالمنظمة بإعتبار هم العملاء تركئ

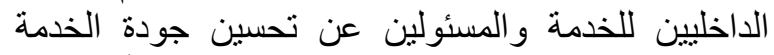
المقدمة (صالح، 2014؛ شعشاعة، والخد 2004). ويبدأ التركيز

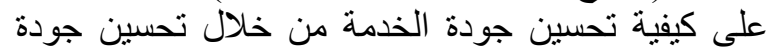

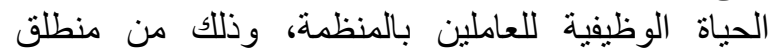

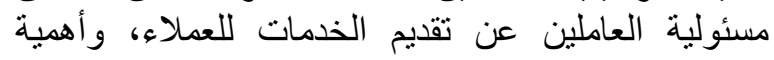

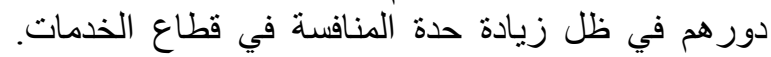

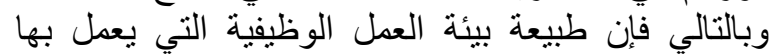

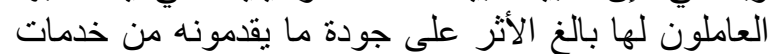

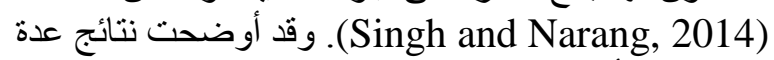
دراسات التأثير الإيجابي لجودة الحياة الوظيفية على جودة ألى

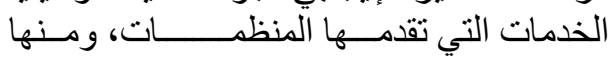

Mohamad and Mohamad (2012); Mohamad et al., (2016) and Tuwei (2017)

إستناداً للعرض السابق، وفي ظل محدودية الدر اسات

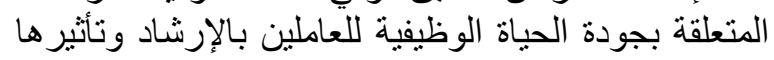

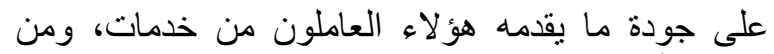

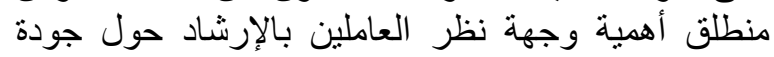
الخدمة المقدمة بإعتبار هم مصدر تلقدية تقديم الخدمة الإرشادية

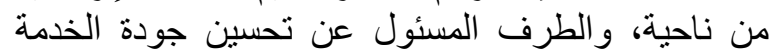

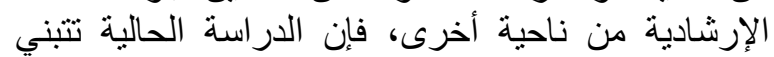

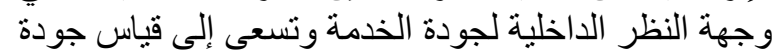

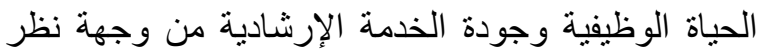

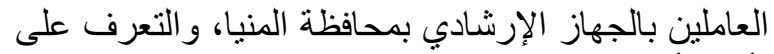
تأثثير أبعاد جودة الحياة الوظيفية على جودة الإنية الخدمة

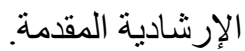

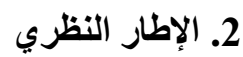

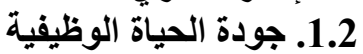
لقد صار ينظر إلي الجودة على أنهاء آداة إداة إستر اتيجية لتحقيق كفاءة وفعالية آداء العمل داخل المنظمات النظات المختلفة (Jain and Gupta, 2004)

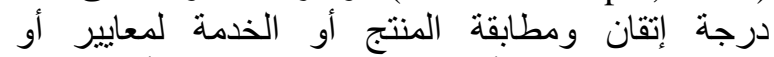

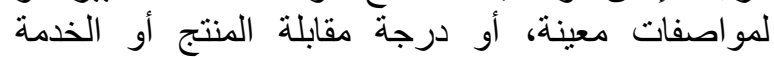

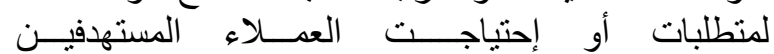
(Dursun et al., 2013; Manjunatha and و ويقصد بالحياة الوظيفية

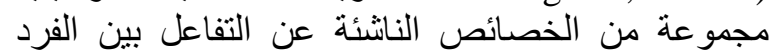
و المنظمة، والتي تمثل الجوانب الإيجابية وغير الإيجابية
وتمثل الموارد البشرية أهم الموارد الإستراتيجية

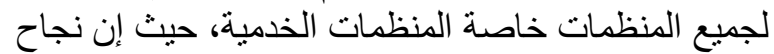
تللك المنظمات في تحقيق أهدافها يتوقف على الإنى الإستخدام

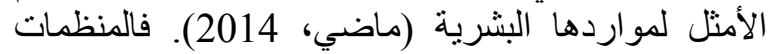
الخدمية تعتمد على إيمان العاملين بها بالخدمات بات الثية المقدمة

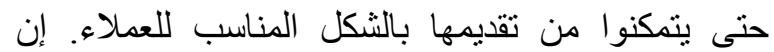

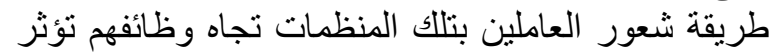

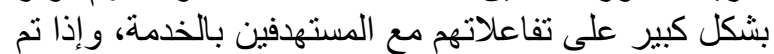

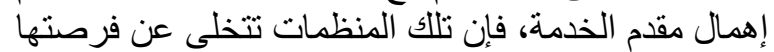
في تقديم خدمة أفضل للعملاء المستهدفين بالخدمة

. (Santercole, 1993)

وتعتبر جودة الحياة الوظيفية (QWL) أحد أهم

العوامل المؤثرة في إدارة الموارد البشرية، والتئة التي تستند

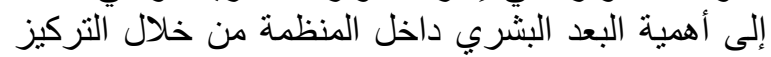

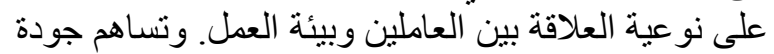
الحياة الوظيفية في تحسين آداء الفرد و المنظمة كلينة كلئ ويتمثل الهدف الأسأسي لجودة الحياة الوظيفية في تحسين

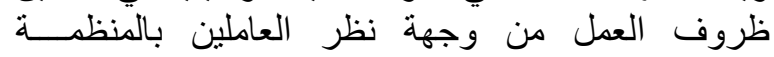
.(Gaur, 2015; Pisheh, 2012)

وتشير جودة الحياة الوظيفية إلى توفير المنظمة

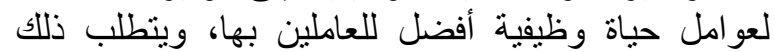
إنتهاج سياسات المو ارد البشرية التي تمكن من توفير المين حياة وظيفية تشبع حاجات العاملين وتحقق آداء أفضل للمنئن المنظمة.

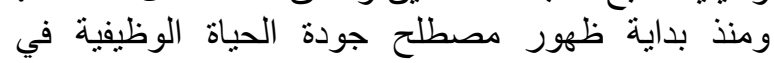
سبعينات القرن العشرين، تركزت فلمة فحواه حول جعل بيئة

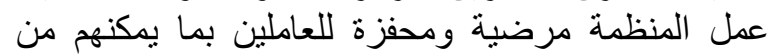

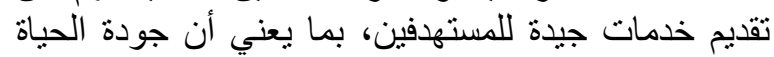

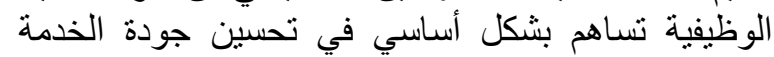

المدركة (Cohen et al., 2007; Viljoen, 2012). وتعتبر منظمات الإرشاد الزراعي الفاعل الرئيسي

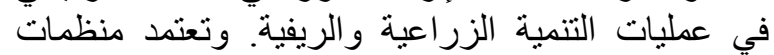

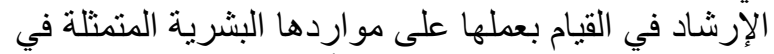
العاملين المسئولين عن تحقيق أهداف العمل الإرشادي التئي (Mulinge and Mueller, 1998)

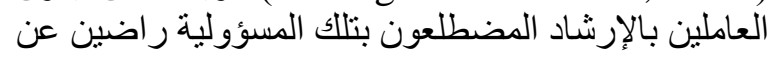

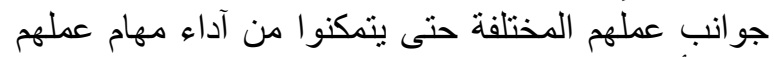
بشكل أكثر فعالية وكفاءة (Banmeke and Ajayi, 2005).

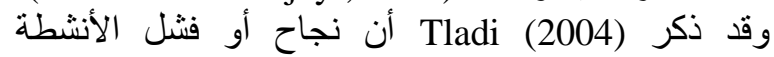
والبرامج الإرشادية يعتمد على الآداء الفاح الفعال للعاملين

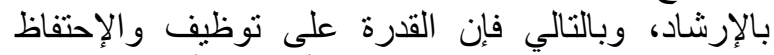

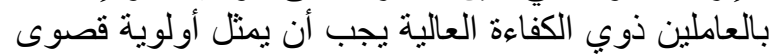

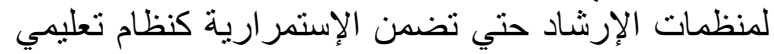
فعال وناجح (Arnold and Place, 2010). وفي ظل سعي المنظمات إلى تحسين مستوى خدماتها

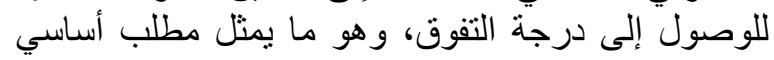

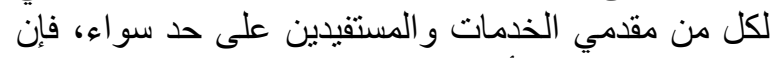

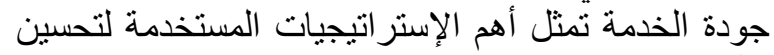

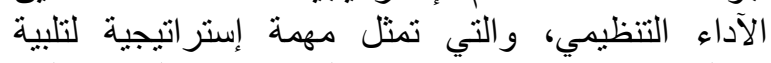

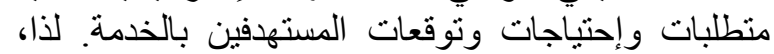


Swamy et al., 2015)

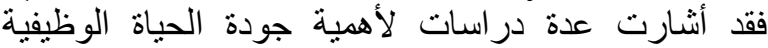

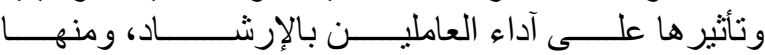
.Azril et al. (2010); Gougheri et al. (2014)

2.2. جودة الخدمة الإرشادية الزراعية

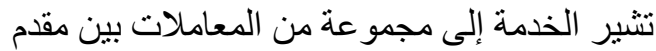

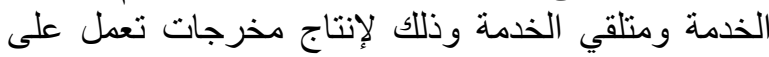
إرضاء العميل (شعشاعة، 2004)، وينظر إلى الخى الخدمات التيات

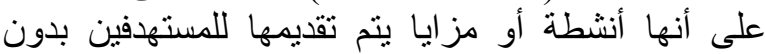

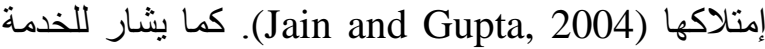

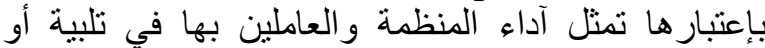
تجاوز الوعود الضمنية التي تم تقديمها طو ال فترة الخداء (Viljoen, 2012). وتتمثل الفروق بين الفئ الخدمة والمنتج في كل من الطبيعة غبر الملموسة للخدمة أي لا بمكن لمسها الخها أو الاحتفاظ بها، وعدم القابلية للتجزئة أبي عدم إمكانية لإنية

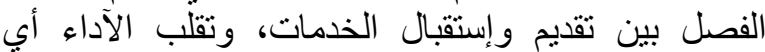
إختلاف آداء الخدمة حسب الوقاب الوقت أو مقدم الخدمة، و الفناء أي عدم إمكانية الإحتفاظ بالخدمات وإن إستخدامها لاحقاً في أوقات الحاجة (Naik et al., 2010). وتعرف جودة الخدمة بأنها مدى تلبية الخدمة الخداء

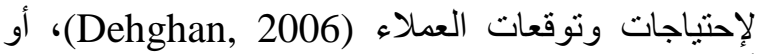

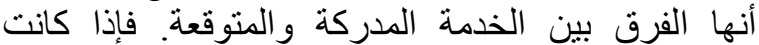
التوقعات أكبر من الآداء الفعلي، تكون الجودة الفية المدركة Service غير مرضية وتتجسد فجوة جودة الخداء الغية (Parasuraman et al., 1985) Quality Gap تعرف جودة الخدمة من وجهة نظر العاملين بالمنظمة على المعا

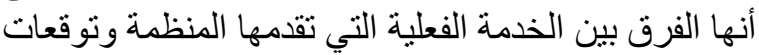

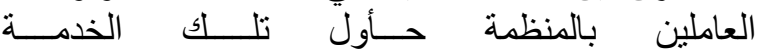
Lewis et al. وذكر (Munhurrun et al., 2010) (1994) مجموعة من المزايا التي تعود على منظمات الخدمات عندما تسعى لتحقيق جودة الخدي الخدمة منها وجئ وجود

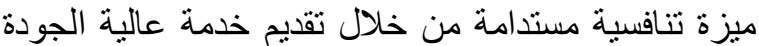

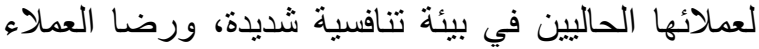

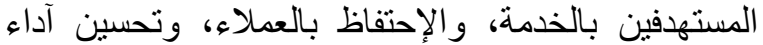
المنظمة وصورتها بالمجتمع. وقد أوضح (2010) Daniel and Berinyuy أن نقطة البداية في تطوير جودة الخدمات هي القياس، وذللك التهات

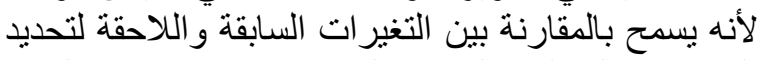

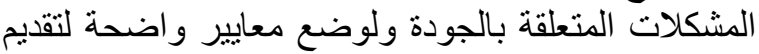

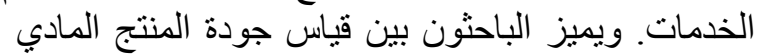
وبين قياس جودة الخدمة، حيث إن للأخير تحديات بات خاصنة

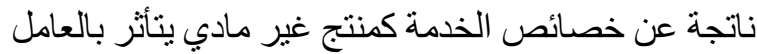
البشري من جهة مقدم الخدمة ومن جهة المستفيد منها (صالح، 2014).

وقد شهدت ثمانينيات القرن العشرين بداية وضع مقاييس مختلفة لقياس جودة الخدمة، وإنطلقت نسبة كبنة كبيرة من الدراسات في هذا المجال من كتابات الثناثي

(Parasuraman, Zeithaml and Bery)(1985,1988)
المرتبطة بالوظيفة كما يدركها العاملون بالمنظمـة .(Sojka, 2014) وقد إتفق العديد من الباحثين على أن جودة الحياة

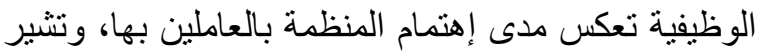

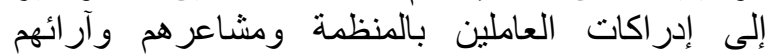

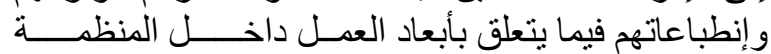
(Nekouei et al., 2014; Afşar, 2014;

ومنذ بداية ظهور الدصطلح، تم تعريف جودة الحياة الوظيفية من واقع لعزية

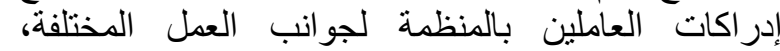

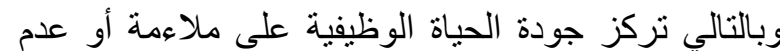

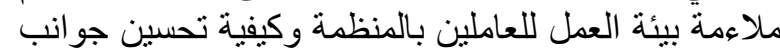

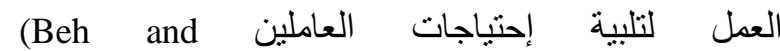
Heskett et al. ويشيرير Rose,2007;Verma,2015) (1994) إلى جودة الحياة الوظيفية على أنها: جودة الخدمة

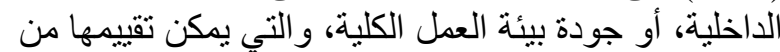

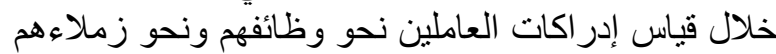

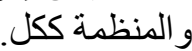
وقد بدأت فكرة جودة الحياة الوظيفية في الظهور التدريجي في سياق ظروف العمل في نهاية خمسينات

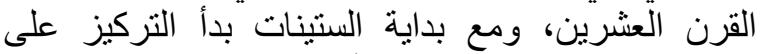

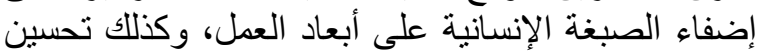
ظروف العمل للعاملين. وظهر ملئه الإعلح العطلح وكودة الحياة الوظيفية لأول مرة عام 1972 خلال العاملين المؤتمر الدولي

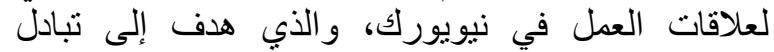

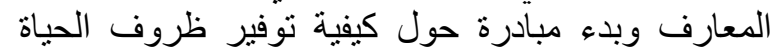

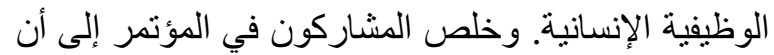

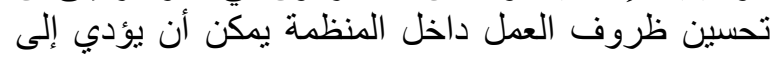

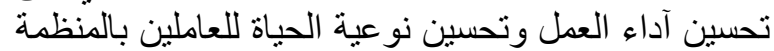
(Gayathiri and Ramakrishnan, 2013; ويشير Hose et al, 2006) مصطلح جودة الحياة الوظيفية أصبح بديلاً لعدة مفاهيم

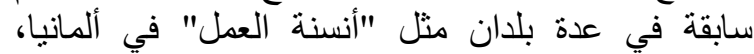
و "تحسين ظروف العمل" في فرنسا، و و"حماية العاملين" المانيا" في بعض دول أوروبا الثرقية.

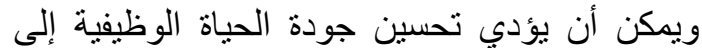

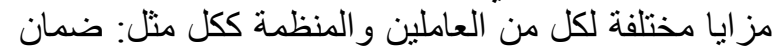
الإستخدام الكامل لإمكانات العاملين العالين مما يحسن من كفل كفاءة

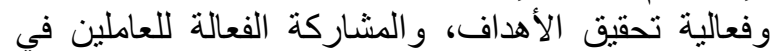

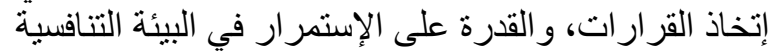

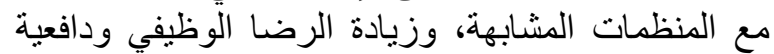

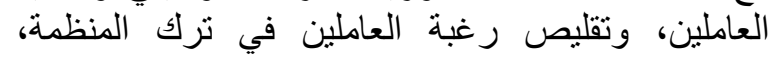

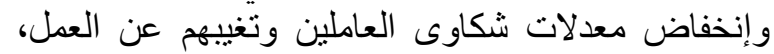

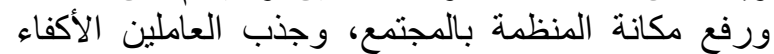

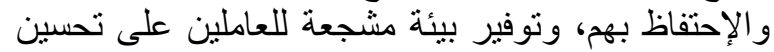

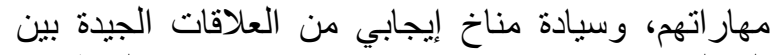

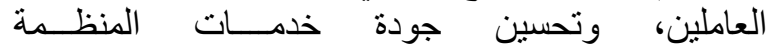
(Srivastava and Kanpur, 2014; Gaur, 2015; 
الوظيفية ونوقعاتهم حول تللك الأبعاد.

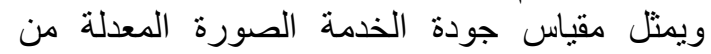
مقياس SERVQUAL ليناسب قياس جودة الخدمة من ون وجهة نظر العاملين بالمنظمات الخدمية، ويتكون من الجين 19

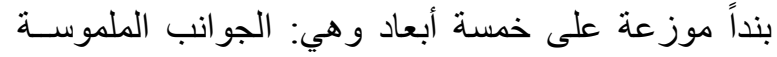

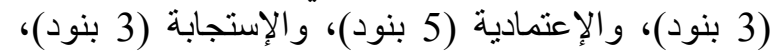

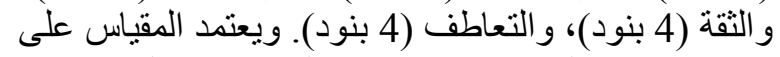

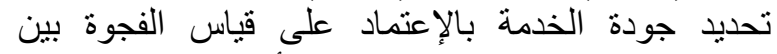

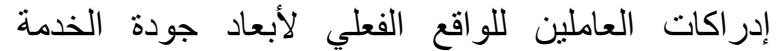
وتوقعاتهم حول تللك الأبعاد. وقد تم جمع البيانات بإستخدام إستمارة الإستبيان

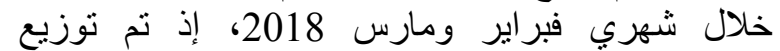
الإستبيان على جميع العاملين بالجهاز الإرشادي بمحافظة المنيا و عددهم 295 فرداً، و إستجاب منهم

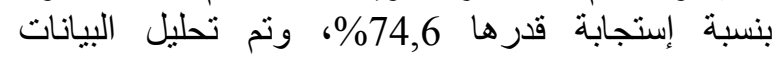
بإستخدام مجموعة البرامج الإحصائية للعلوم الإجتماعية

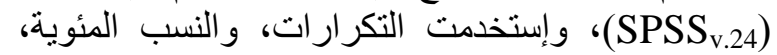
والمتوسط الحسابي، وتحليل الإنحدار المتعدد لتحليل

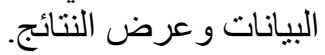

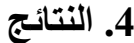

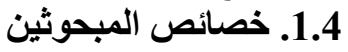

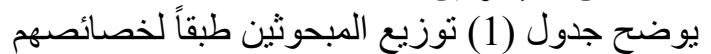

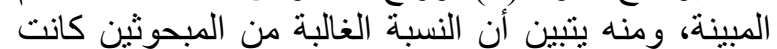

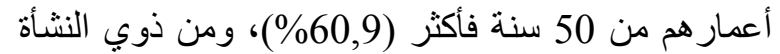

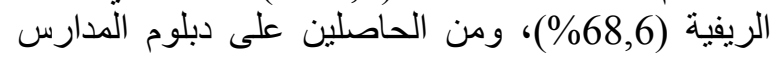

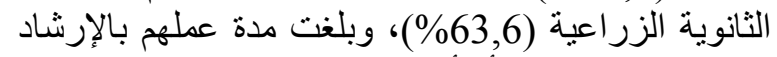

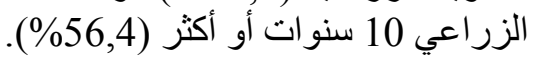

جدول (1): توزيع المبحوثين طبقاً لخصائصهم المبينة (ن= 220).

\begin{tabular}{|c|c|c|c|}
\hline$\%$ & العدد & الخصائص & م \\
\hline \multicolumn{3}{|c|}{ 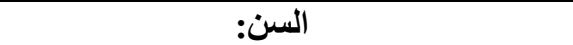 } & 1 \\
\hline 39,1 & 86 & أقل من 50 سنة & \\
\hline 60,9 & 134 & 50 سنة فأكثر & \\
\hline \multicolumn{3}{|c|}{ 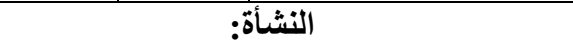 } & 2 \\
\hline 68,6 & 151 & ريفية & \\
\hline 31,4 & 69 & 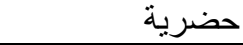 & \\
\hline \multicolumn{3}{|c|}{ المؤهل الدراسي: } & 3 \\
\hline 63,6 & 140 & دبلوم & \\
\hline 36,4 & 80 & بكالوريوس & \\
\hline \multicolumn{3}{|c|}{ مدة العمل بالإرشاد الزراعي: } & 4 \\
\hline 43,6 & 96 & أقل من 10 سنو ات & \\
\hline 56,4 & 124 & 10 سنوات فأكثر & \\
\hline
\end{tabular}

2.4. جودة الحياة الوظيفية من وجهة نظر العاملين بالجهاز الإرشادي بمحافظة المنيا الوزئ

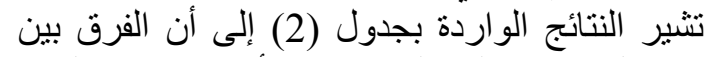
المتوسط العام لإدراك المبحوثين لأبعاد جودة الحئ الحياة
والذين إنتهى عملهم إلى تطوير المقياس الأكثر إنتشاراً

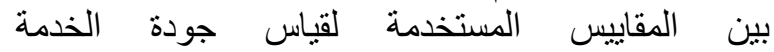
SERVQUAL)

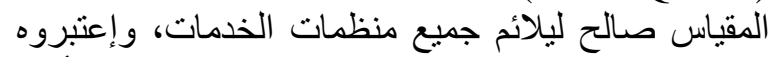

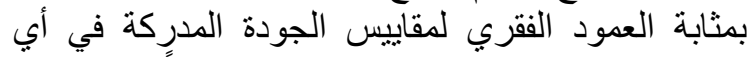

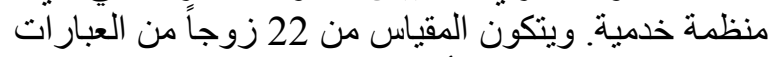

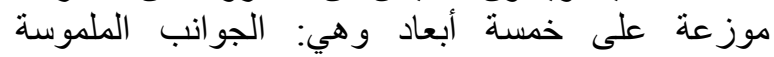
Tangibles

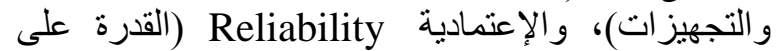
تأدية الخدمة بدقة وعلى الإعلى الوجه الصحيح)، والإستجابة Responsiveness

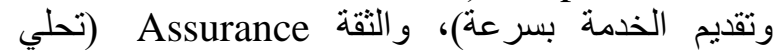
العاملين بالمعرفة والمعاملة الجيدة والقدرة على العيلة الإيحاء

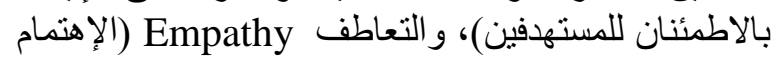

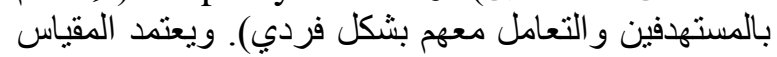

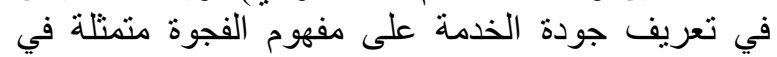

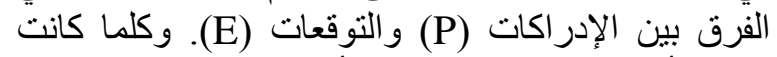

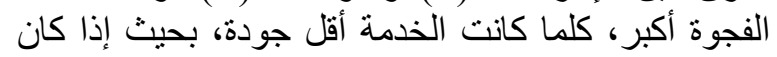

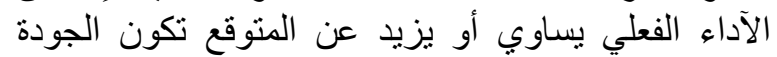

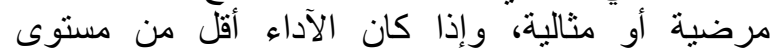
التوقعات تكون الجودة غير مرضية ودون الآداء مسنوى (Parasuraman et al., 1985; التوقعات .Parasuraman et al., 1988)

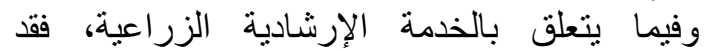

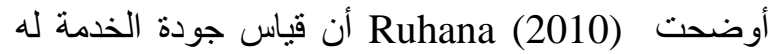

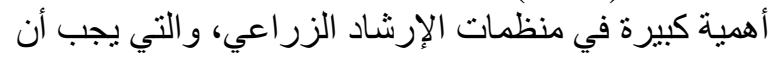

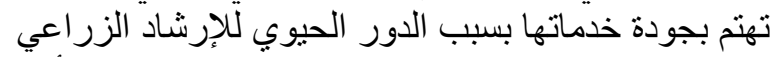

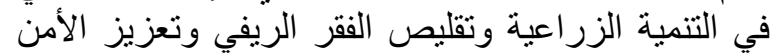

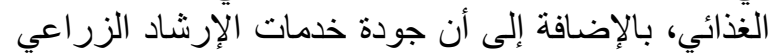
من أهم مؤشر ات نجاح منظمات الإرشاد الزراعي ككل. الإرثاد الزراعي

إستخدمت الدراسة الحالية مقياس جودة الحياة

\section{3. طريقة إجراء البحث}

(Kandasamy and Sreekumar, 2009; الوظيفية

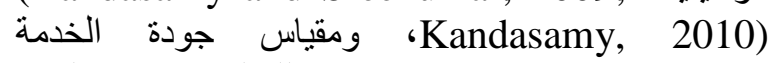

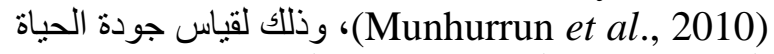

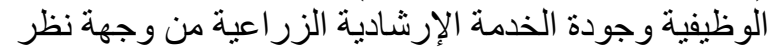

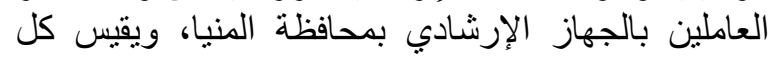

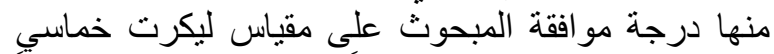
الأبعاد يتدرج ما بين موافق جداً (5) إلى غير مو افق جداً

ويعتبر مقياس WRKLFQUAL واسنة وأحدث مقاييس

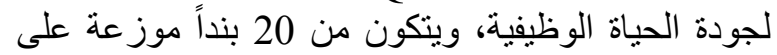

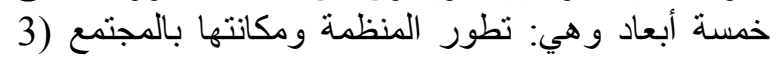

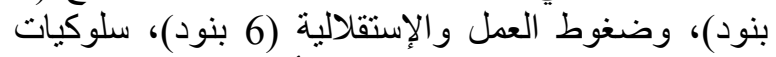

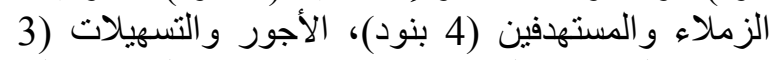

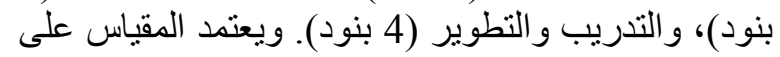

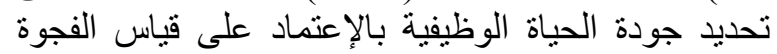

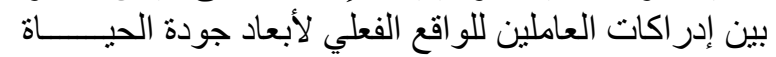


الفجو ات الخاصة بتو افر معايير الأمان و السلامة للعاملين

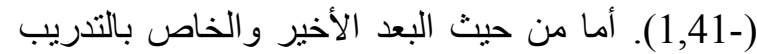
والتطوير، فقد كانت الفجوة الأكبر بين التوقعات والآير الآداء

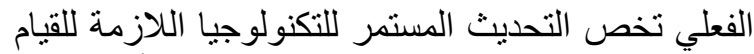

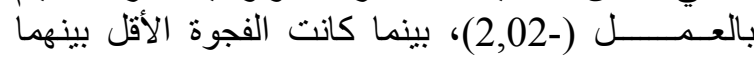

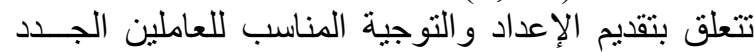
(0,35-)

\section{4. جودة الخدمة الإرشادية الزراعية من وجهة نظر الإرئ}

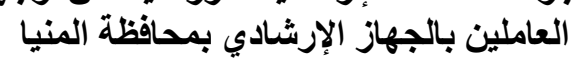

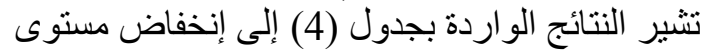

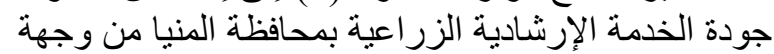

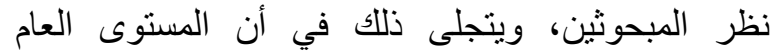

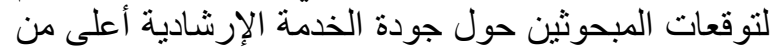

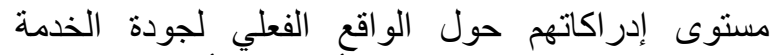

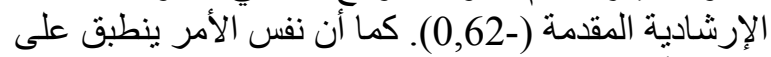

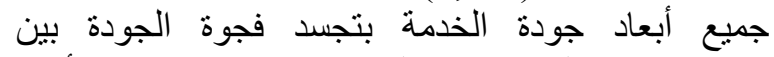

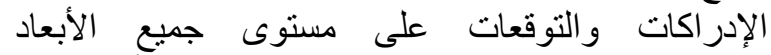

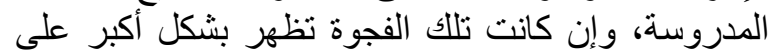

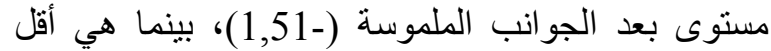

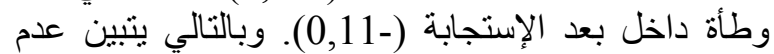

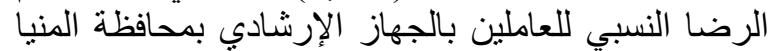

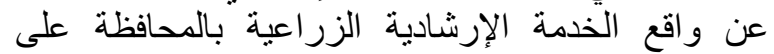
المستوى الإجمالي خاصة فيما يتعلق بالتسهيلات التراعة المادية

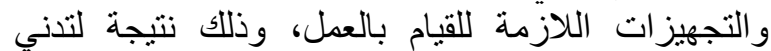
إدر اكاتهم لو اقع جودة الخدمة الإرشادية المقدمة في مقابل توقعاتهم حول جودة تلك الك الخدمات.

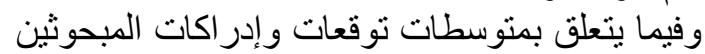

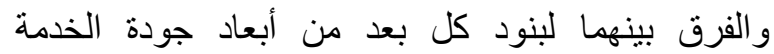

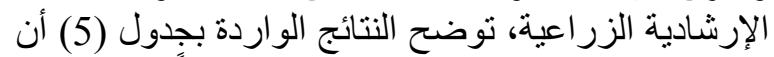

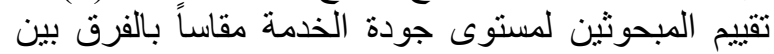

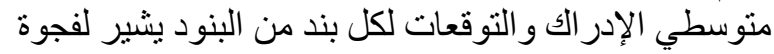

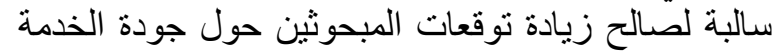

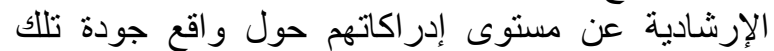

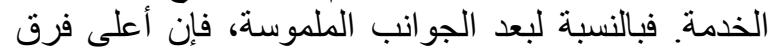

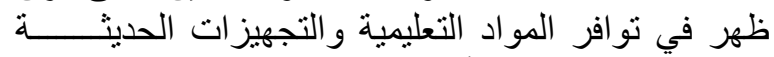
(1,72)، بينما ظهر أقل فرق (-1,27) في جاذبية تلكية التهان

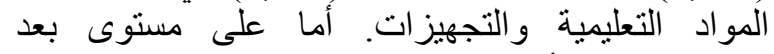
الاعنمادية، فإن أكبر فرق تعلق بتقديم الخدمات الإرشادية التراتية

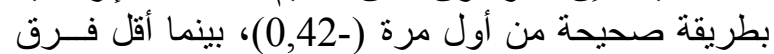

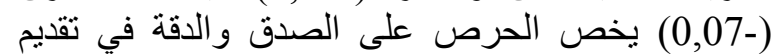

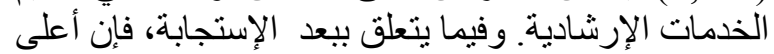

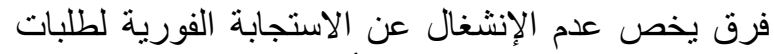
المسترشدين (-0,14)، بينما أقل فرق (لإن (-0,09) يقابل الرغبة الدائمة في تقديم الخدمات الإرشادية للمسترشدين.

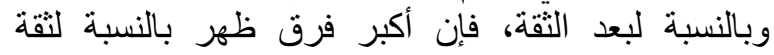

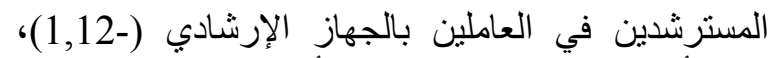

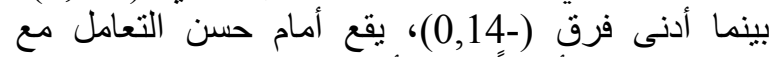

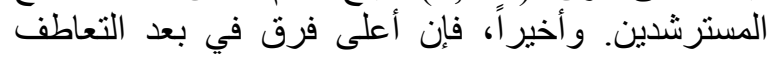

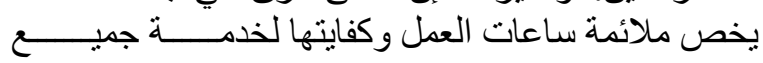

جدول (2): متوسطات توقعات و إدراكات المبحوثين والفرق بينهما لأبعاد جودة الحياة الوظيفية.

\begin{tabular}{|c|c|c|c|}
\hline $\begin{array}{l}\text { P- الفرق } \\
\text { E) }\end{array}$ & \begin{tabular}{|} 
الإلادر|أك) \\
(P)
\end{tabular} & $\begin{array}{c}\text { التوقعات (E) } \\
\text { (E) }\end{array}$ & أبعاد جودة الحياة الوظيفية \\
\hline $0,85-$ & 3,63 & 4,48 & تطور المنظمة ومكانتها بالمجتمع \\
\hline $1,19-$ & 3,22 & 4,41 & ضغوط العمل والإستقلالية \\
\hline $0,39-$ & 4,13 & 4,52 & سلوكيات الزملاء و المستهـفين \\
\hline $2,11-$ & 2,59 & 4,70 & الأجور والتسهيلات \\
\hline $0,99-$ & 3,37 & 4,36 & التكريب و التظوير \\
\hline $1,11-$ & 3,38 & 4,49 & المتوسط العام \\
\hline
\end{tabular}

الوظيفية ومثيله بالنسبة للتوقعات هو فرق سالب (-1,11)،

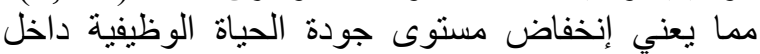

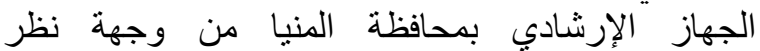

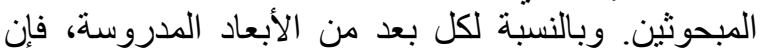

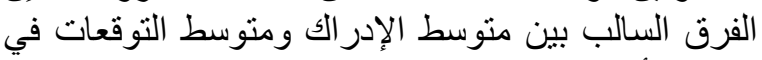

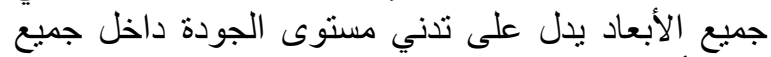

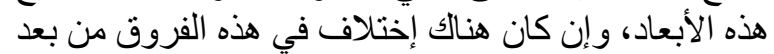

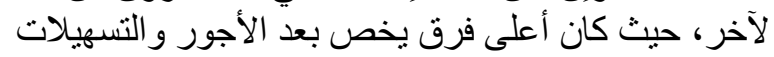

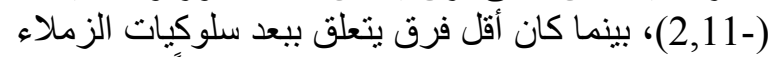

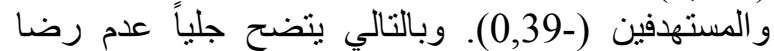
العاملين بالجهاز الإرشادي بمحافظة المنيا عن جميع أبعاد

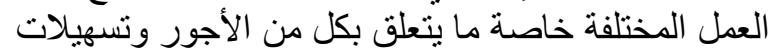

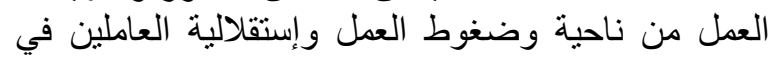

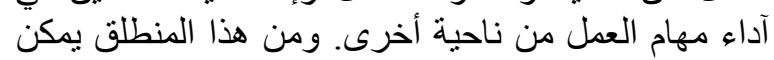

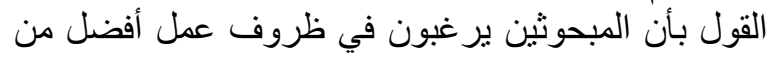

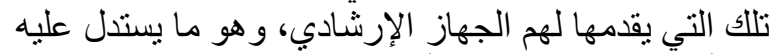

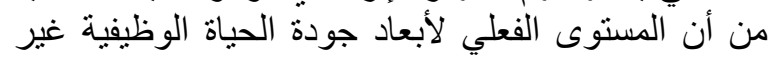
مرضي ودون مستوى توقعات المبحوثنين.

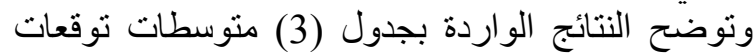

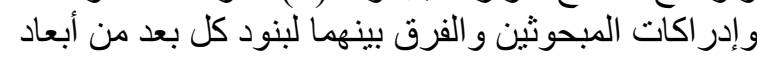

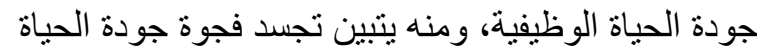

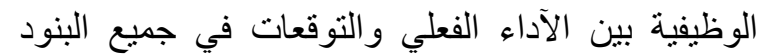

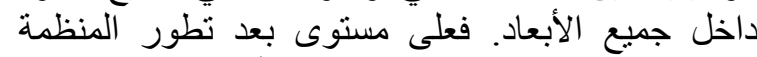
الإرشادية ومكانتها، تمثلت الفجوة الأكبر بين التوان التوقعات

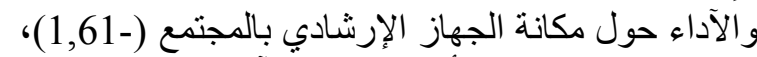

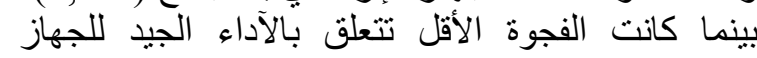

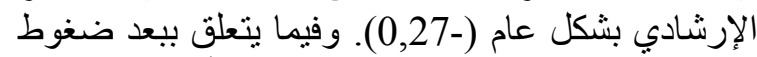

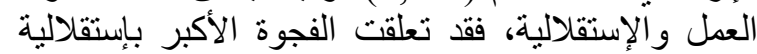
العاملين في آداء مهام العمل (-1,98)، بينما كانت العان الفجوة الأقل مرتبطة بتوزيع العاملين على ولى وظائف تناسب

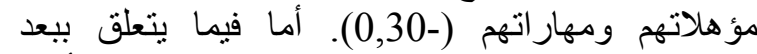
سلوكيات الزملاء و المستهدفين، فقد كانت الفجوة الأكبر الأنير

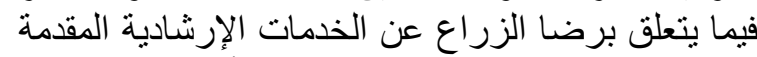

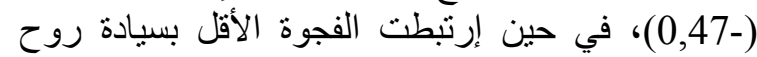

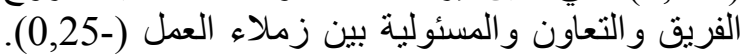
ومن حيث بعد الأجور والتسهيلات، فقد كاندان التعلت أكبر

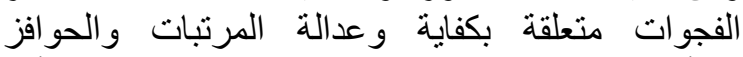
والتأمين الصحي والمعانشات (-2,56)، في مقابل أقل 
جدول (3): متوسطات توقعات وإدراكات المبحوثين والفرق بينهما لبنود كل بعد من أبعاد جودة الحياة الوظيفية.

\begin{tabular}{|c|c|c|c|c|c|}
\hline $\begin{array}{l}\text { الفرق } \\
\text { (P-E) }\end{array}$ & $\begin{array}{l}\text { الإدراك( } \\
\text { (P) }\end{array}$ & التوقعات & 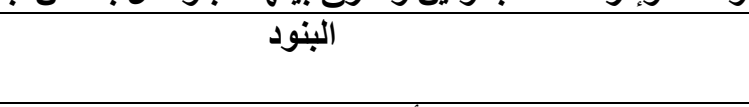 & & الأبعاد \\
\hline $0,67-$ & 3,82 & 4,49 & تطور الجهاز الإرشادي للأفضل بصورة مستمرة & 1 & \multirow{3}{*}{ والمنظمة } \\
\hline $0,27-$ & 4,15 & 4,42 & الآداء الجيد للجهاز الإرشادي بشكل عام & 2 & \\
\hline $1,61-$ & 2,93 & 4,54 & مكانة الجهاز الإرشادي المرتفعة بالمجتمع & 3 & \\
\hline $0,69-$ & 3,59 & 4,28 & تتاسب مهام العمل مع قدرات و إمكانيات العاملين & 4 & \multirow{6}{*}{ والإستقلالية } \\
\hline $0,74-$ & 3,65 & 4,39 & كفاية و إنتظام ساعات العمل & 5 & \\
\hline $1,54-$ & 2,89 & 4,43 & المهام الوظيفية مشوقة ومحفزة & 6 & \\
\hline $0,30-$ & 3,92 & 4,22 & توزيع العاملين على وظائف تتاسب مؤ هلاتهم ومهار اتهم & 7 & \\
\hline $1,94-$ & 2,73 & 4,67 & مهام العمل ترضي العاملين وتتناسب مع إهتماماتهم & 8 & \\
\hline $1,98-$ & 2,53 & 4,51 & إستقلالية العاملين في آداء مهام العمل & 9 & \\
\hline $0,41-$ & 4,17 & 4,58 & تميز رؤساء العمل بروح الفريق و التعاون و المسئولية & 10 & \multirow{4}{*}{ والزملوكيات } \\
\hline $0,25-$ & 4,24 & 4,49 & تميز زملاء العمل بروح الفريق و التعاون و المسئولية & 11 & \\
\hline $0,43-$ & 4,18 & 4,61 & تعامل المسترشدين بشكل جيد مع العاملين بالإرشاد & 12 & \\
\hline $0,47-$ & 3,94 & 4,41 & رضا الزراع عن الخدمات الإرشَادية المقدمة & 13 & \\
\hline $2,56-$ & 2,26 & 4,82 & كفاية و عدالة المرتبات و الحو افز و التأمين الصحي و المعاثشات & 14 & \multirow{3}{*}{ و التسهيلات } \\
\hline $2,35-$ & 2,38 & 4,73 & كفاية ومناسبة وسائل الإنتقال اللازمة للقيام بالعمل & 15 & \\
\hline $1,41-$ & 3,15 & 4,56 & تو افر معايير الأمان و السلامة للعاملين & 16 & \\
\hline $0,61-$ & 3,78 & 4,39 & التدريب المناسب و المستمر للعاملين & 17 & \multirow{4}{*}{ والتطويب } \\
\hline $0,95-$ & 3,32 & 4,27 & تقييم آداء العاملين بصورة مستمرة & 18 & \\
\hline $0,35-$ & 3,96 & 4,31 & تقديم الإعداد و التوجية المناسب للعاملين الجدد & 19 & \\
\hline $2,02-$ & 2,43 & 4,45 & التحديث المستمر للتكنولوجيا اللازمة للقيام بالعمل & 20 & \\
\hline
\end{tabular}

وتوقعاتهم بشأنها، وذللك من أجل الإرتقاء بمستوى جودة الخدمة الإرشادية الزر اعية بمحافظة المنيا.

4.4 تأثير أبعاد جودة الحياة الوظية الزية الزية على جودة الخدمة

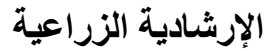

إستخدم تحليل الإنحدار المتعدد للتعرف على إنى تأثئير

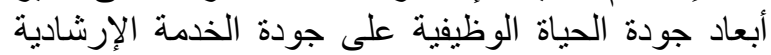

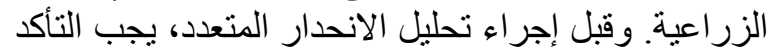

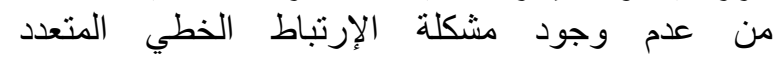
Multicollinearity

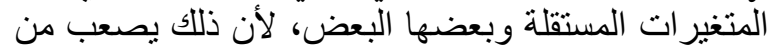

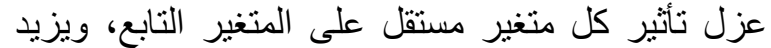

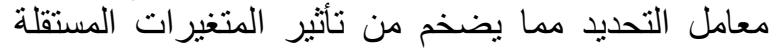

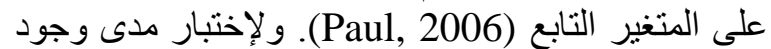

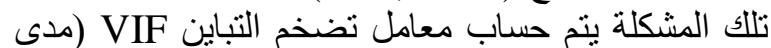
زيادة تباين معاملات الإنحدار نتيجة الإرتباط لئن بين

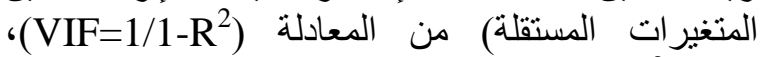

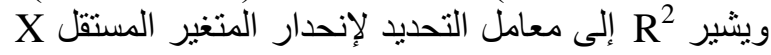

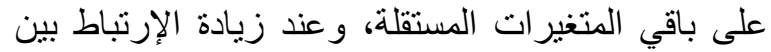

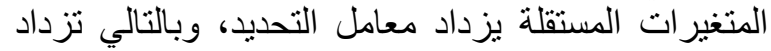

المصدر: إستمار ات الإستبيان

جدول (4): متوسطات توقعات وإدراكات المبحوثين والفرق بينهما لأبعاد جودة الخدمة الإششادية الزراعية.

\begin{tabular}{|c|c|c|c|}
\hline $\begin{array}{r}\text { الفرق) } \\
\text { (P-E) }\end{array}$ & $\begin{array}{c}\text { الإدراك(اك) } \\
\text { (P) }\end{array}$ & التوقعات & أبعاد جودة الخدمة| \\
\hline $1,51-$ & 2,84 & 4,35 & الجوانب الملموسة \\
\hline $0,24-$ & 4,19 & 4,43 & الاعتمادية \\
\hline $0,11-$ & 4,38 & 4,49 & الإستجابة \\
\hline $0,57-$ & 3,89 & 4,46 & الثقة \\
\hline $0,67-$ & 3,65 & 4,32 & التعاطف \\
\hline $0,62-$ & 3,79 & 4,41 & المتوسط العام \\
\hline
\end{tabular}

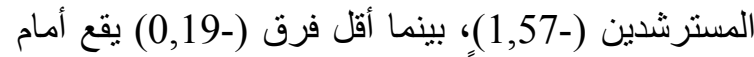
إهتمام العاملين إهتماماً شخصيًا بالمسترشدين.

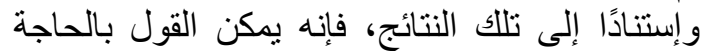

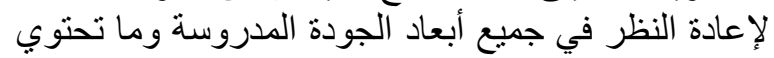

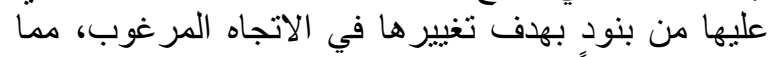

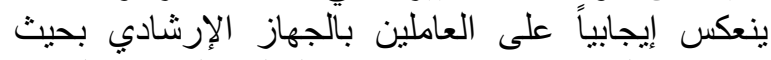
تتلاشى الفروق بين إدراكهم الفعلي لجودة الإنيادي الخدمة 
جدول (5) : متوسطات توقعات وإدراكات المبحوثين والفرق بينهما لبنود كل بعد من أبعاد جودة الخدمة الإرشادية الزراعية.

\begin{tabular}{|c|c|c|c|c|c|}
\hline الفرق (P-E) & الإدراك (P) & التوقعات (E) & 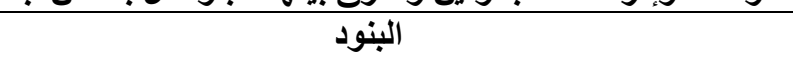 & & الأبعاد \\
\hline $1,72-$ & 2,71 & 4,43 & تو افر المو اد التعليمية و التجهيزات الحديثة & 1 & \multirow{3}{*}{ الملموسنة } \\
\hline $1,27-$ & 2,98 & 4,25 & جاذبية المو اد التعليمية و التجهيزات & 2 & \\
\hline $1,51-$ & 2,85 & 4,36 & تتاسب المو اد التعليمية و التج كيزات مع الخذمات المقدمة & 3 & \\
\hline $0,24-$ & 4,21 & 4,45 & الوفاء بالو عود التي يقدمها الجهاز الإرشادي للمسترشدين & 4 & \multirow{5}{*}{ 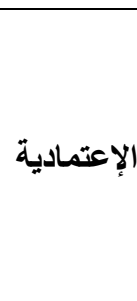 } \\
\hline $0,19-$ & 4,13 & 4,32 & التعاطف مع مشاكل المسترشدين و الإهتمام بحلها & 5 & \\
\hline $0,42-$ & 4,07 & 4,49 & تقديم الخدمات الإرشادية بطريقة صحيحة من أول مرة & 6 & \\
\hline $0,19-$ & 4,32 & 4,51 & تقديم الخدمات طبقاً لحاجات المسترشدين و الوعود التي قدمت لهم & 7 & \\
\hline $0,07-$ & 4,21 & 4,28 & الحرص على الصدق و الدقة في تقديم الخدمات الإرشادية & 8 & \\
\hline $0,11-$ & 4,23 & 4,34 & السر عة في تقديم الخدمات الإرشّادية للمسترشدين & 9 & \multirow{3}{*}{ 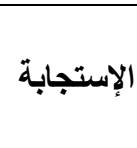 } \\
\hline $0,09-$ & 4,53 & 4,62 & الرغبة الدائمة في تقديم الخدمات الإرشادية للمسترشدين & 10 & \\
\hline $0,14-$ & 4,39 & 4,53 & عدم الإنشغال عن الاستجابة الفورية لطلبات المسترشدين & 11 & \\
\hline $1,12-$ & 3,31 & 4,43 & العاملين بالجهاز الإرشادي موضع ثقة المسترشدين & 12 & \multirow{4}{*}{ الثقة } \\
\hline $0,85-$ & 3,47 & 4,32 & شعور المسترشدين بالأمان في التعامل مع العاملين & 13 & \\
\hline $0,14-$ & 4,51 & 4,65 & حسن التعامل مع المسترشدين & 14 & \\
\hline $0,19-$ & 4,28 & 4,47 & المعر فة الكافية و التدريب الللازم لتقديم الخدمات الإرشادية & 15 & \\
\hline $0,68-$ & 3,54 & 4,22 & التعامل بشكل فردي مع مشكلات كل مسترشد طبقاً لظروفه & 16 & \multirow{4}{*}{ التعاطف } \\
\hline $0,22-$ & 4,13 & 4,35 & التفهم التام لإحتياجات المسترشدين المختلفة & 17 & \\
\hline $0,19-$ & 4,28 & 4,47 & مصالح المسترشدين هي أولى إهتمامات الجهاز الإرشادي & 18 & \\
\hline $1,57-$ & 2,67 & 4,24 & ملائمة ساعات العمل وكفايتها لخدمة جميع المسترشدين & 19 & \\
\hline
\end{tabular}

جدول (6): معامل تضخم التباين لأبعاد جودة الحياة الوظيفية.

\begin{tabular}{|c|c|}
\hline التباين(VIF) معامل تضخم & أبعاد جودة الحياة الوظيفية \\
\hline 1,771 & تطور المنظمة ومكانتها \\
\hline 1,880 & ضغوط العمل و الإستقلالية \\
\hline 1,292 & سلوكيات الزملاء والمستهوفين \\
\hline 1,228 & الأجور والتسهيلات \\
\hline 2,203 & التدريب والتطوير \\
\hline
\end{tabular}

إمكانية التنبؤ بجودة الخدمة الإرشادية عن طريق أبعاد

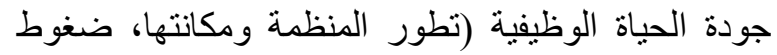
العمل و الإستقلالية، سلوكية (نطورت الزمات الزملاء و والمستهدفين،

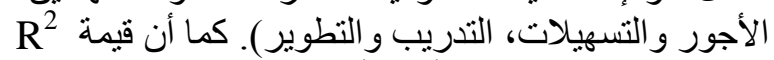

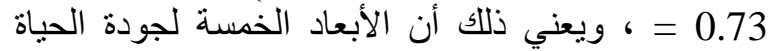

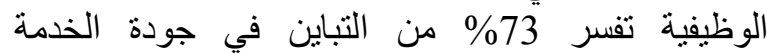
الإرشادية الزر اعية.

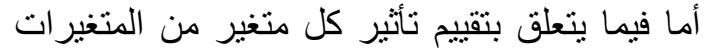

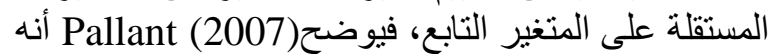
لمقارنة تأثير المتغيرات المستقلة على المتغير التابع يتم
قيمة معامل تضخم التباين وتقل دقة القياس أي دقة

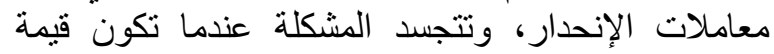

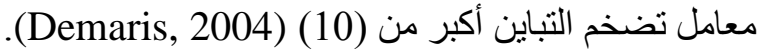
ويمكن التغلب على تللك المشكلة عن طريق تمركز المتغير

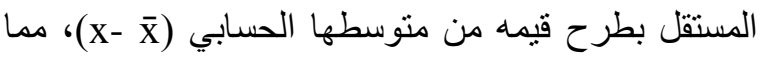
يقلل من الإرتباط البيني للمتغيرات المستقلة بيعضها البعض (Robinson and Schumacker, 2009). ولتطبيق تحليل الانحدار المتعدد، تم تنفيذ ثلاث

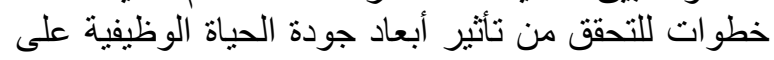

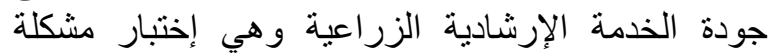

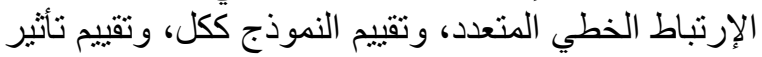

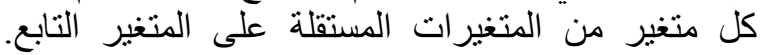

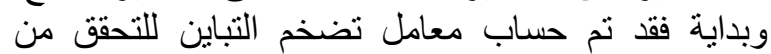

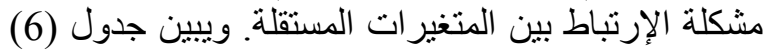

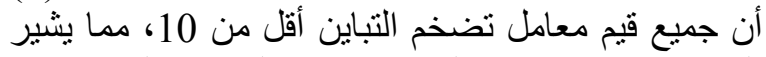

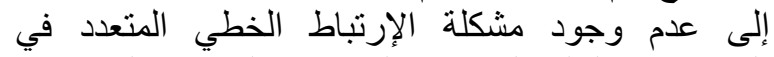

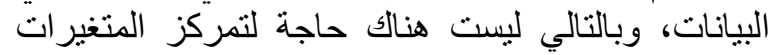
المستقلة.

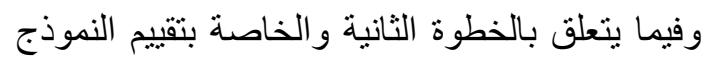

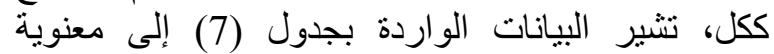
النموذج بشكل إجمالي (F=49.58, p> 001)، بما يعني الئي 
بمحافظة المنيا من واقع إدراكات العاملين ومن ثم

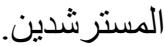

وبالأخذ في الإعنبار للعو ائق المحتملة المتعلقة

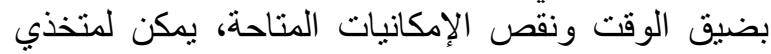

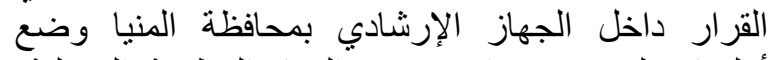

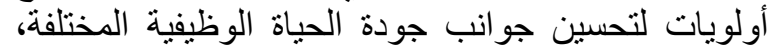

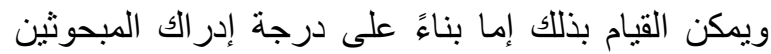

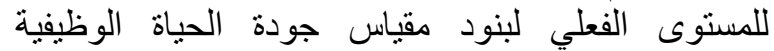

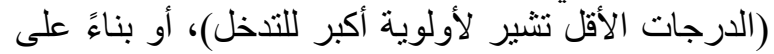

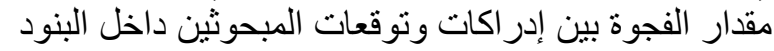

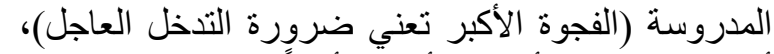

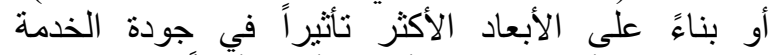
الإرشادية (الأولوية لبنود الأبعاد الأكثر نأثئيراً).

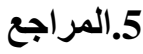

شعشاعة، حاتم غازي (2004). قياس جودة الخدمات

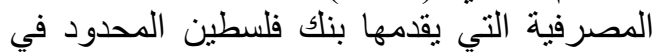

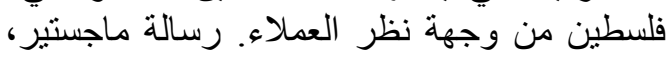

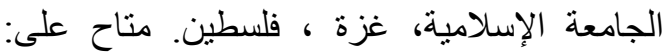
http://alqashi.com/th/th92.pdf

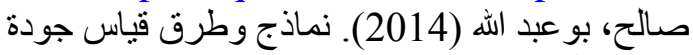
الخذمة: در اسة تطبيقية على خدمات مؤسسة برة بريد

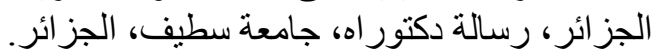

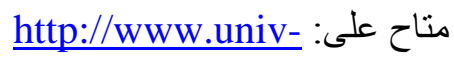
setif.dz/Tdoctorat/facultes/facultes/fseg /2014/bouabdallahsalah.pdf

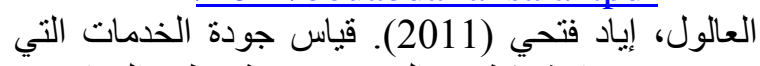

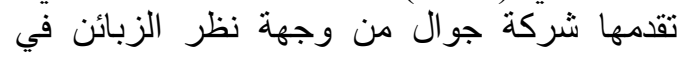
محافظات قطاع غزة، رسالة ماجستير ، جامعة عزئ الأزهر - غزة، فلسطين. متاح على على مالى http://www.alazhar.edu.ps/Library/aatt achedFile.asp?id_no=0044734 عباس، هشام عبد الله (2005). قباس جودة خدمة خدمات المكتبات الجامعية: دراسة تطبيقية علي خئي خدمات مكتبات جامعة الملك عبد العزيز بجده، مبلمة مكتبة

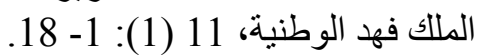
ماضي، خليل إسماعيل (2014). جودة الحية الحياة الوظيفية

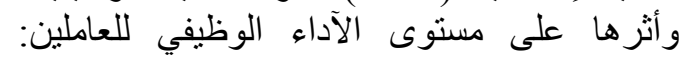

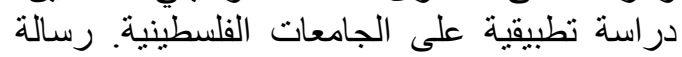

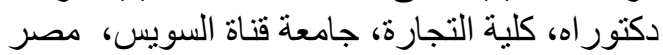
متاح على: مكاه

\section{REFERENCES}

Afşar S. (2014). Impact of the quality of work life on organizational commitment: A comparative study on academicians working for state and foundation Universities in Turkey, Int'1 J. Soc. Sci., 3(4): 124-152.
جدول (7): نتائج تحليل الإنحدار المتعدد لتأثير أبعاد جودة الحياة الوظيفية على جودة الخدمة الإرشادية الزراعية.

\begin{tabular}{|c|c|c|c|}
\hline المعنويةي & قيمة & |الإنحدار (B) معاملات & أبعاد جودة الحياة الوظيفية \\
\hline 0,025 & 2,263 & 0,144 & تطور المنظمة ومكانتها \\
\hline 0,004 & 2,946 & 0,182 & ضغوط العمل والإستقلالية \\
\hline 0,011 & 2,556 & 0,135 & سلوكيات الزملاء و المستهلفين \\
\hline 0,000 & 7,470 & 0,386 & الأجور والتسهيلات \\
\hline 0,033 & 2,145 & 0,148 & التدريب والتطوير \\
\hline
\end{tabular}

ملحوظة: F=49.58, p< 001 , R

إستخدام معاملات الإنحدار المعيارية (ß)، بينما تستخدم معاملات الإنحدار غير الإندار المعيارية في حالة الإلة الدر اسات التي تهدف إلى الوصول لإلعارل المعادلات خط الإنحدار.

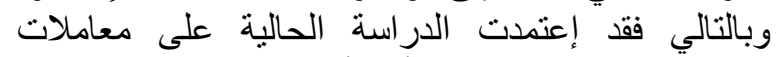

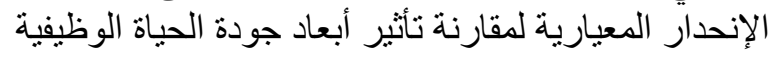

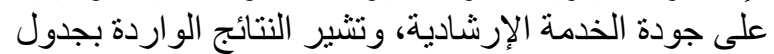

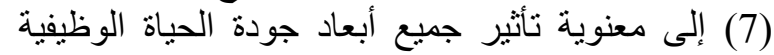

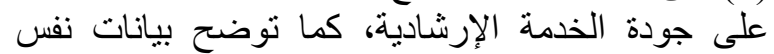

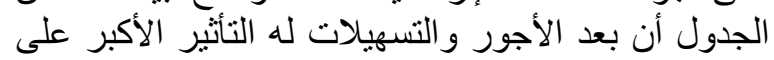

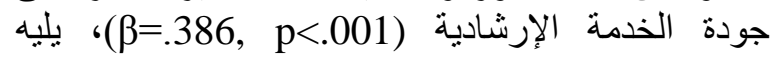

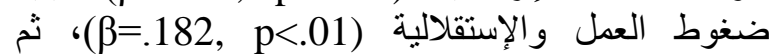

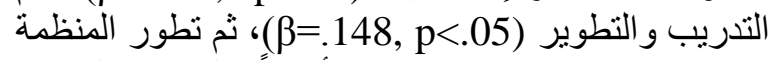

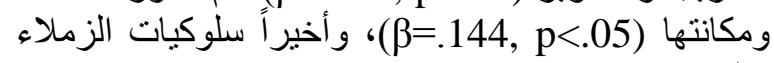

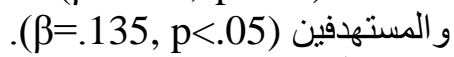
الخلاصة والتوصيات

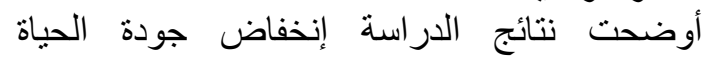

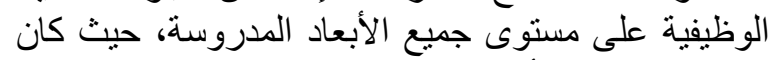

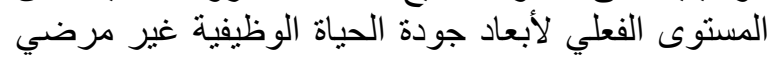

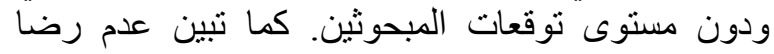
المبحوثين عن و اقع الخدمة الإرشادية الزر اعية باتئ بالمحافظة،

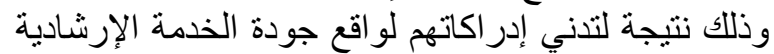

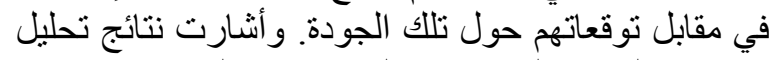

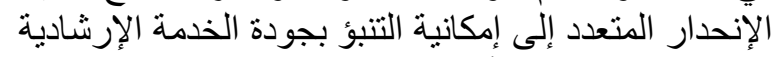

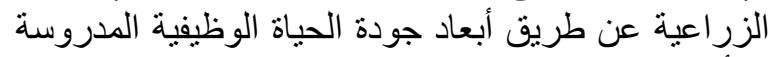

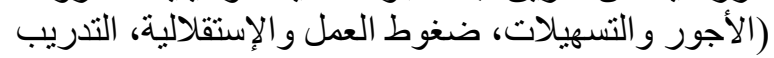

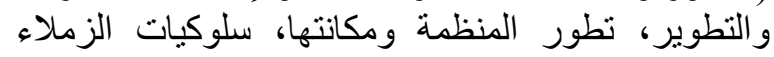
و المستهدفين). وبناءً على نتائج الدراسة الحالية، يمكن القول بأن

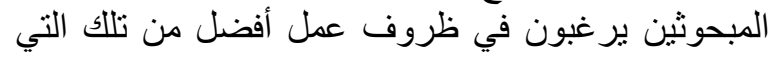

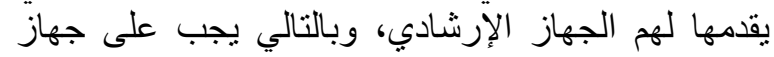

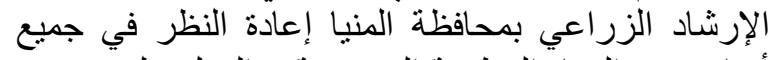

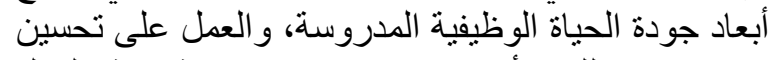

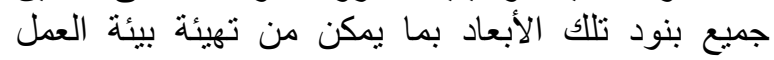

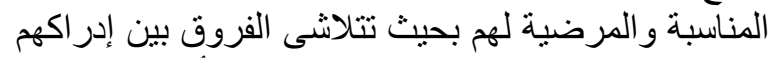

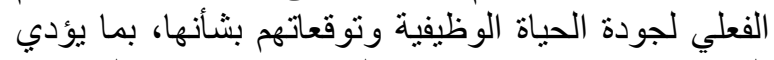

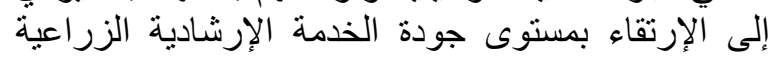


Arnold S. and Place N. (2010). Career influences of agricultural extension agents, J. Agric. Edu.,51 (1): 11 - 21.

Azril H., Jegak U., Asiah M., Azman A., Bahaman A., Othman J. and Thomas K. (2010). Can quality of work life affect work performance among government agriculture extension officers? A case from Malaysia, J. Soc. Sci., 6 (1): $64-73$.

Banmeke T. and Ajayi M. (2005). Job satisfaction of extension workers in Edo state agricultural development programme (EDADP), Nigeria, Int'1 J.Agric. Rural Develop., 6 (1): 202-207.

Beh L. and Rose R. (2007). Linking QWL and job performance: Implications for organizations, Perform. Improv., 46 (6): 3035.

Cohen B., Kinnevy S. and Dichter M. (2007). The quality of work life of child protective investigators: A comparison of two work environments. Children and Youth Services Review, 29(4): 474-489.

Daniel C. and Berinyuy L. (2010). Using the SERVQUAL model to assess service quality and customer satisfaction, Master Thesis, Umea University,Umea, Sweden. Available at: http://umu.divaportal.org/smash/get/diva2:327600/FULLT EXT01.pdf

Dehghan A. (2006). Relationship between service quality and customer satisfaction, Master Thesis, Lulea University of Technology, Sweden. Available at: http://www.divaportal.org/smash/get/diva2:1020291/FULL TEXT01.pdf

Demaris A. (2004). Regression with social data, John Wiley \& Sons, Inc., Hoboken, New Jersey, USA.

Dursun T., Oskayba K. and Gökmen C. (2013). The quality of service of the distance education, Procedia - Soc. and Behav. Sci., 103: $1133-1151$.

Gaur A. (2015). A comparative study on quality of work life, job satisfaction and performance of employees of selected public and private sector banks in Gujarat, $\mathrm{PhD}$ Thesis, Sardar Patel University, Gujarat, India. Available at:

http://shodhganga.inflibnet.ac.in/handle/106 $\underline{03 / 75480}$
Gayathiri R. and Ramakrishnan L. (2013). Quality of Work life - linkage with job satisfaction and performance, Int' $1 \mathrm{~J}$. Bus. Manag. Inven., 2 (1): 1-8.

Gougheri H., Karami S. and Rezvanfar A. (2014). Analyzing the relationship between quality of work life and agricultural extension experts' task and contextual performance, Iran Agric. Exten. Educ. J., 9 (2): 129-144.

Heskett J., Jones T., Loveman G., Sasser W. and Schlesinger L. (1994). Putting the service-profit chain to work. Harvard Bus. Rev., 72 (2): 164-174.

Huzzard J. (2003). The convergence of the quality of working life and competitiveness: A current Swedish literature review, National Institute for Working Life, Stockholm. Available at: http://journals.lub.lu.se/index.php/aio/articl e/download/16396/14856

Jain S. and Gupta G. (2004). Measuring service quality: SERVQUAL vs. SERVPERF scales, VIKALPA, 29 (2): 25-37.

Kandasamy I. (2010). Expected quality of work life and the impact of the gap between perception and expectation of QWL attributes on ECSQ and turnover intentions among hotel employees. PhD Thesis, Goa University, Goa, India.

http://shodhganga.inflibnet.ac.in/handle/106 03/12689? mode $=$ full

Kandasamy I. and Sreekumar A. (2009). WRKLFQUAL: A tool for measuring quality of work life. Res. Pract. in Human Resource Manag.,17(1),59-70.

Lewis B., Orledge J. and Mitchell V. (1994). Service quality: Students' assessment of banks and building societies, Int ${ }^{`} 1 \mathrm{~J}$. Bank Market., 12(4): 3-12.

Manjunatha K. and Shivalingaiah D. (2004). Customer's perception of service quality in libraries. Ann. Library and Inf. Studies, 51 (4): 145-151.

Mohamad M. and Mohamad W. (2012). A Model of quality of work life, life satisfaction and service quality. Asian J.Bus. Res., 2 (2): 38-51.

Mohamad W., Mohamad M., Salleh H., Mat M and Yusof Y. (2016). Quality of work life and quality of nursing care, The Soc. Sci., 11 (12): 3024-3031. 
Muindi F. and Obonyo P. (2015). Quality of work life, personality, job satisfaction, competence, and job performance: A critical review of literature. Europ. Sci. J., 11 (26): 223-240.

Mulinge M. and Mueller C. (1998). Employee job satisfaction in developing countries: The case of Kenya, World Develop., 26 (12): 2181-2199.

Munhurrun P., Naidoo P. and Bhiwajee S. (2010). Measuring service quality: Perceptions of employees, Global J. Bus. Res., 4 (1): 47-58.

Naik C., Gantasala S. and Prabhakar G. (2010). Service quality (Servqual) and its effect on customer satisfaction in retailing, Europ. J. Soc.Sci., 16 (2): 231-243.

Nekouei M. Othman M. Masud, J. and Ahmad A. (2014). Quality of work life and job satisfaction among employee in government organizations in Iran,J.Basic and Appl. Sci.Res. 4 (1):217-229.

Pallant J. (2007). SPSS survival manual, third edition, Open University Press, England.

Parasuraman A., Zeithaml V. and Berry L. (1985). A conceptual model of service quality: Its implications for the future research, J. Mark., 49(4) 41-50.

Parasuraman A., Zeithaml V. and Berry L. (1988). Servqual: A multiple-item scale for measuring customer perceptions of service quality, Journal of Retailing, 64 (1): 12-37.

Paul R. (2006). Multicollinearity: Causes, effects and remedies. Indian Agri. Stat. Res. Instit., New Delhi, India. Available at: http://iasri.res.in/seminar/AS299/ebooks/2005-

2006/Msc/trim2/3.\%20Multicollinearity$\%$ 20Causes,Effects\%20and\%20RemediesRanjit.pdf

Pisheh M. (2012). Quality of work life (QWL) and job stress among Iran public employees. Afr. J. Bus. Manag., 6 (28): 8296-8308.

Robinson C. and Schumacker R. (2009). Interaction effects: Centering, variance inflation factor, and interpretation issues. Multiple Linear Regression Viewpoints, 35(1): 6-11.

Rose R., Beh L., Uli J. and Idris K. (2006). Quality of work life: Implications of career dimensions,J. Soc. Sci.,2 (2), 61-67.
Ruhana F. (2010). Service quality measurement of agricultural extension in Kpsdmp-Kp regency of Garut, Int`1 J. Kybernology, 1(2): 1-13.

Santercole G. (1993). Quality of work life in the hotel industry, M.Sc. Thesis, Rochester Institute of Technology, New York, USA. Available at:

http://scholarworks.rit.edu/cgi/viewcontent. cgi? article $=8446 \&$ context $=$ theses

Singh S. and Narang R. (2014). Quality of work life and service quality, In: Goyal, A. (Ed.), Innovations in services marketing and management, IGI Global, USA. Available at: http://www.irmainternational.org/viewtitle/87984/

Sojka L. (2014). Specification of the quality of work life characteristics in the Slovak economic environment. Sociológia, 46 (3): 283-299.

Srivastava S. and Kanpur R. (2014). A study on quality of work life: Key elements and its implications. IOSR J. Bus. Manag., 16 (3): 54-59.

Swamy D., Nanjundeswaraswamy T. and Rashmi S. (2015). Quality of work life: Scale development and validation, Inte'l J. Caring Sci., 8 (2): 281-300.

Tladi F. (2004). Job content and training needs of agricultural extension agents in southcentral Botswana. J. Int'l Agric. Exten. Edu., 11 (3): 33-39.

Tuwei R. (2017). Effect of work life balance on service delivery in selected county referral hospitals in Kenya, Int'l J.Econ., Comm. Manag., 5 (10): 359-371.

Verma A. (2015). A study on quality of work life among employees of diesel Locomotive works, Varanasi, Int'l J. Manage.Soc. Sci. Res. Rev., 1 (8): 19-24.

Viljoen A. (2012). Perceived service delivery and productivity in the food and beverage sector in Potchefstroom, M.Sc. Thesis, North West University,Potchefstroom, South Africa.

Available at: http://dspace.nwu.ac.za/bitstream/handle/10 394/9541/Viljoen_AH_TOC.pdf?sequence= $1 \&$ isAllowed=y 